\title{
Activation of the Human Immunodeficiency Virus Type 1 Long Terminal Repeat by Vaccinia Virus
}

\author{
KATHLEEN A. STELLRECHT, ${ }^{1} \dagger$ KIRK SPERBER, ${ }^{2}$ AND BEATRIZ G.-T. POGO ${ }^{1}$ * \\ Department of Neoplastic Diseases ${ }^{1}$ and Division of Clinical Immunology, ${ }^{2}$ \\ Mount Sinai School of Medicine, New York, New York 10029-6574
}

Received 7 October 1991/Accepted 18 December 1991

\begin{abstract}
A variety of DNA viruses are known to activate gene expression directed by the long terminal repeat (LTR) of human immunodeficiency virus type 1 (HIV-1). In light of the proposed use of recombinant vaccinia virus for HIV-1 vaccines, evaluation of the role of vaccinia virus in HIV-1 activation is warranted. To investigate whether vaccinia virus induces HIV LTR-directed gene expression, transient expression assays in Jurkat cells persistently infected with vaccinia virus $\left(J_{\text {vac }}\right)$ using plasmid DNA containing the LTR linked to the bacterial chloramphenicol acetyltransferase (CAT) gene were performed. CAT activity in $\mathbf{J}_{\text {vac }}$ cells was always recorded, although the level appears to fluctuate independently of virus titers. Dual intracytoplasmic staining and fluorescence-activated cell sorter analysis showed that CAT activity was expressed in the infected cells. CAT expression was not due to plasmid replication, since plasmid DNA extracted from $J_{\text {vac }}$ cells 48 h after transfection was restricted only by enzymes which recognize methylated sequences, indicating a prokaryotic source for the DNA. These findings suggest that a factor(s) present in vaccinia virus-infected cells is capable of activating the LTR of HIV-1.
\end{abstract}

Vaccinia virus has been proposed for use in recombinant vaccine strategies for numerous viruses, including human immunodeficiency virus type 1 (HIV-1) (for a review, see reference 20). However, vaccination can result in systemic infections, especially in individuals with immune dysfunctions, including AIDS. One such example occurred after smallpox vaccination of an asymptomatic army recruit infected with HIV-1 (28). Within 3 weeks of vaccination, this asymptomatic HIV-1 infection developed into AIDS-related complex and disseminated vaccinia virus infection. More recently, the use of a recombinant vaccinia virus for immune treatment of AIDS patients in France (24) may have resulted in the death of three of these patients (10). It is obvious that vaccinia virus is still an important pathogen of our times, and hence, it is essential to identify genes in the vaccinia virus genome that are involved in virulence and HIV-1 activation.

Although vaccinia virus has been studied extensively, the molecular mechanisms for its pathogenesis are not completely understood (for a review, see reference 37). Cells persistently infected with vaccinia virus have been useful for studying the effect of the virus on cellular functions $(23,25$, 26). Recently, a persistent infection of the human T-lymphocyte cell line, Jurkat, has been established in this laboratory (36a). Infections of these cells are associated with the activation of certain cellular genes, including interleukin 2 (IL-2), IL-6, and the IL-2 receptor (IL-2R) (36a). Because activation of this cell line renders it permissive for the expression of reporter genes directed by the HIV-1 long terminal repeat (LTR) (33), persistent infections of these cells can be useful for investigating the effects of vaccinia virus on HIV replication. In this report, evidence that indicates that vaccinia virus is capable of activating reporter genes under the direction of the HIV LTR is presented. It is expected that this model system will help to explain the basis

\footnotetext{
* Corresponding author.

$\dagger$ Present address: Department of Clinical Microbiology, Albany Medical Center Hospital, Albany, NY 12208.
}

of vaccinia pathogenesis and HIV-1 activation, which in turn will aid in engineering safer vaccine vectors.

\section{MATERIALS AND METHODS}

Cells, virus, and reagents. Jurkat cells (a gift from $M$. Siekevitz, Mount Sinai School of Medicine) and Jurkat cells persistently infected with vaccinia virus, designated $\mathbf{J}_{\text {vac }}$, were cultured in RPMI 1640 medium (GIBCO) supplemented with $10 \%$ fetal calf serum and antibiotics. Virus infectivity was monitored by plaque assay in L-cell monolayers (7). In some experiments, 2\% Bacto-phytohemagglutinin M (PHA) (Difco Laboratories, Detroit, Mich.) was added to the culture medium.

Transfection experiments. The following plasmids were used: pHIV/CAT, which contains 671 bp of the HIV-1 LTR ligated to the chloramphenicol acetyltransferase (CAT) gene (a gift from M. Siekevitz); $\mathrm{pSV}_{2} / \mathrm{CAT}$, which has the simian virus 40 promoter linked to the CAT gene; and $\mathrm{pSV}_{\mathrm{o}} / \mathrm{CAT}$, which contains the promoterless CAT gene. Plasmid DNA was isolated by using Qiagen columns (Qiagen Inc., Chatsworth, Calif.) according to the methods described by the manufacturer. Cells were transfected with plasmid DNA by using DEAE-dextran (33). Briefly, $10 \mu \mathrm{g}$ of DNA, in a $0.5-\mathrm{ml}$ solution of $25 \mathrm{mM}$ Tris-buffered saline ( $\mathrm{pH} 7.4$ ) with $0.7 \mathrm{mM} \mathrm{Ca}^{2+}, 0.5 \mathrm{mM} \mathrm{Mg}^{2+}$, and $0.5 \mathrm{mg}$ of DEAE-dextran per $\mathrm{ml}$, was incubated with $5 \times 10^{6}$ cells for $60 \mathrm{~min}$. After 30 $\mathrm{min}, 3 \mathrm{ml}$ of a $50-\mu \mathrm{g} / \mathrm{ml}$ solution of chloroquine in RPMI 1640 medium was added. PHA was added after $24 \mathrm{~h}$ of culture, and the cells were collected after an additional $24 \mathrm{~h}$ of incubation. CAT assays and thin-layer chromatography were performed as described by Gorman et al. (14).

DNA extraction and enzymes. Transfected cells were harvested, washed in phosphate-buffered saline, resuspended in $50 \mathrm{mM}$ Tris ( $\mathrm{pH} \mathrm{7.4)}$ containing 1\% Sarkosyl and $1 \mathrm{mg}$ of proteinase $\mathrm{K}$ per $\mathrm{ml}$, and incubated at $37^{\circ} \mathrm{C}$ overnight. The DNA was extracted sequentially with phenol and chloroform, precipitated with ethanol, and centrifuged in a microcentrifuge for $30 \mathrm{~min}$ at $4^{\circ} \mathrm{C}$. The DNA pellet was resus- 

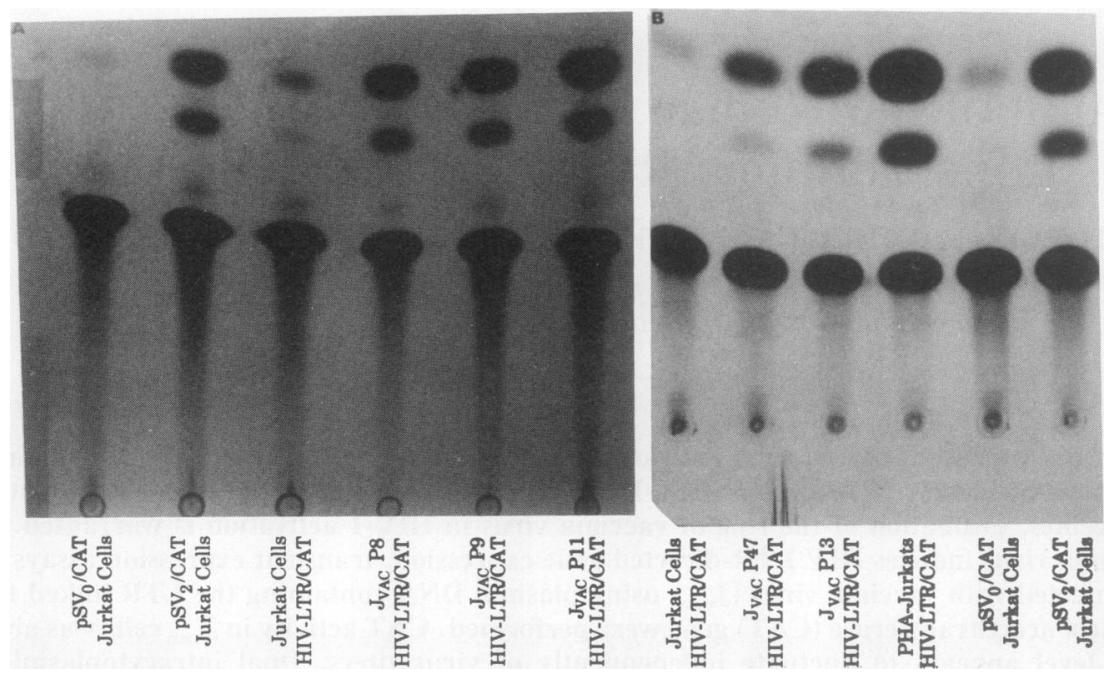

FIG. 1. trans activation of the HIV LTR by vaccinia virus. Jurkat and $\mathrm{J}_{\text {vac }}$ cell lines were transfected with $10 \mu \mathrm{g}$ of pHIV/CAT DNA and maintained for $48 \mathrm{~h}$ at $37^{\circ} \mathrm{C}$. PHA was added $24 \mathrm{~h}$ posttransfection. CAT assays were performed, and the product was analyzed by chromatography on silica gel thin-layer plates. Autoradiographs of two independent experiments (A and B) are shown. Jurkat cells were also transfected with $\mathrm{pSV}_{0} / \mathrm{CAT}$ or $\mathrm{pSV}_{2} / \mathrm{CAT}$ DNA. $\mathrm{P}$, passage number.

pended in $10 \mathrm{mM}$ Tris- $\mathrm{HCl}$ (pH 7.6)-0.1 mM EDTA. Restriction endonucleases DpnI and NdeII, purchased from Boehringer Mannheim, were used according to the manufacturer's specifications.

Agarose gel electrophoresis and hybridization. DNA fragments were separated by electrophoresis in a $1.0 \%$ agarose gel, transferred to nitrocellulose paper by Southern blotting (34), and hybridized with ${ }^{35} \mathrm{~S}$-labeled probes. Probes were prepared by nick translation as described by Rigby et al. (30).

Antibodies and fluorescence-activated cell sorter (FACS) analysis. Vaccinia virus antibodies were obtained from rabbits inoculated with vaccinia virus and labeled with biotinylated goat anti-rabbit immunoglobulin antibody. A fluorescein isothiocyanate-conjugated anti-CAT antibody was obtained from 5 Prime $\rightarrow 3$ Prime (West Chester, Pa.). Viable cells were isolated on a Ficoll gradient $24 \mathrm{~h}$ posttransfection (35). Intracytoplasmic staining and analysis on an Epic S C FACS (Coulter Scientific, Hialeah, Fla.) were performed 24 $\mathrm{h}$ later as previously described (36).

\section{RESULTS}

Activation of the HIV LTR in vaccinia virus-infected cells. The pHIV/CAT, $\mathrm{pSV}_{0} / \mathrm{CAT}$, and $\mathrm{pSV}_{2} / \mathrm{CAT}$ DNAs were transfected into $\mathrm{J}_{\text {vac }}$ or control Jurkat cells. As shown in Fig. 1, little expression of the CAT gene directed by the HIV LTR was observed in Jurkat cells. However, a significant level of expression was seen in $\mathbf{J}_{\mathrm{vac}}$ cells (passages $8,9,11$, 13 , and 47), suggesting that vaccinia virus affects HIV-1 expression. Similar results were obtained in multiple experiments using different cell lines (Fig. 2). PHA, a known activator of both T cells and the HIV LTR, induces expression of the CAT gene directed by the HIV LTR in Jurkat cells to levels similar to those previously reported (33). By comparison, CAT activity in the infected cells equaled or even exceeded that of PHA-stimulated cells as well as that of $\mathrm{pSV}_{2} / \mathrm{CAT}$ in Jurkat cells. As expected, the $\mathrm{pSV}_{0} / \mathrm{CAT}$ was not expressed in either Jurkat or $\mathrm{J}_{\text {vac }}$ cells.

Evaluation of the activation of the HIV LTR-directed
CAT gene in the infected cells at various times after infection demonstrates that during the first week of infection there was little effect on CAT expression, even after $48 \mathrm{~h}$, when viral replication is at its peak (Table 1 ). However, at 10 days after infection, a significant increase in the expression of CAT was observed. The data in Table 1 also demonstrate that, although the level of CAT activity in $\mathbf{J}_{\text {vac }}$ cells fluctuated from passage to passage, a significant increase over that of uninfected cells was always recorded. Comparisons of virus titers and CAT activities in various passages indicate that a high level of infectivity is not necessary for increased CAT expression (Table 1).

Optimization of CAT expression. CAT expression was evaluated in relation to the amount of transfected DNA and the time at which transfected cells were harvested. Figure 3A demonstrates that the level of CAT activity increased proportionally with the amount of transfected DNA. When the level of CAT expression was monitored at different times

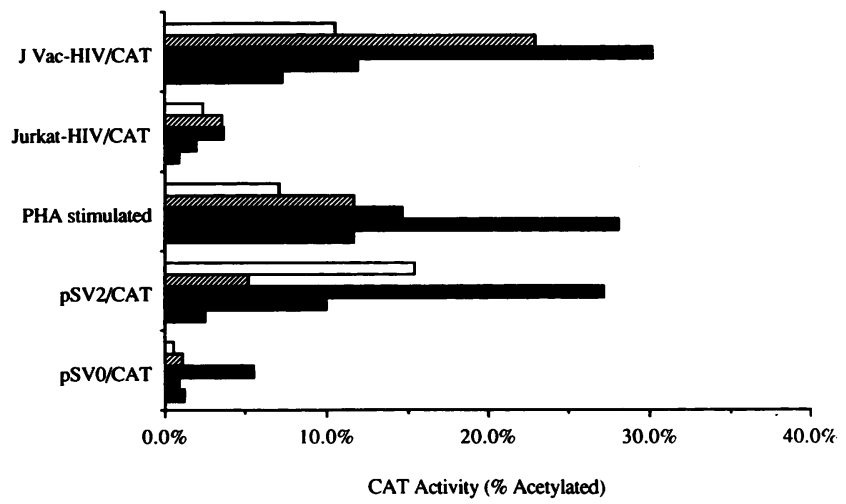

FIG. 2. CAT activity in Jurkat and $\mathrm{J}_{\text {vac }}$ cell lines transfected with pHIV/CAT DNA. Experimental conditions are as described in the legend to Fig. 1. Activity is expressed as percent chloramphenicol acetylated. Bars represent five independent experiments in which all values were normalized to $50 \mathrm{ng}$ of protein. 
A.

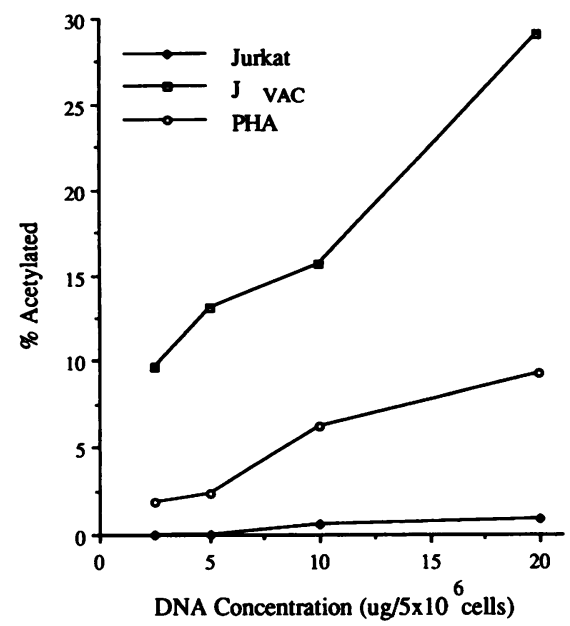

B.

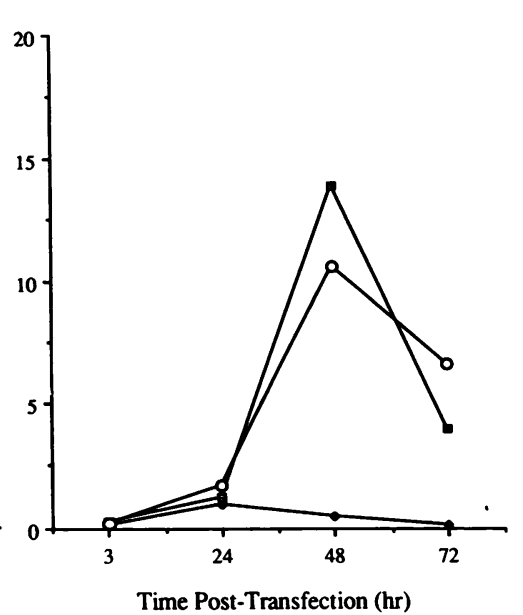

FIG. 3. CAT activity as a function of the amount of transfected DNA and the duration of transient expression. (A) Jurkat and $\mathrm{J}_{\mathrm{vac}}$ cells transfected with the indicated amounts of pHIV/CAT. (B) Jurkat and $\mathrm{J}_{\text {vac }}$ cells transfected with $10 \mu \mathrm{g}$ of pHIV/CAT and harvested at the times indicated. CAT activity was normalized to $10 \mathrm{ng}$ of protein. PHA was added $24 \mathrm{~h}$ posttransfection.

after transfection (Fig. 3B), a significant level of expression between 48 and $72 \mathrm{~h}$ was evident. However, maximal activity was recorded $48 \mathrm{~h}$ posttransfection.

Investigation of plasmid replication. It has been reported that cells infected with poxviruses are capable of replicating transfected plasmid DNA (9). Hence, it was important to determine whether the enhanced CAT activity observed in $\mathrm{J}_{\text {vac }}$ cells was due to an increase in the amount of template DNA rather than to induction of gene expression. For that

TABLE 1. CAT activity in Jurkat cells persistently infected with vaccinia virus

\begin{tabular}{lcc}
\hline $\begin{array}{c}\text { Time, passage, } \\
\text { or treatment }\end{array}$ & PFU/cell & $\begin{array}{c}\text { Relative CAT } \\
\text { activity }^{a} \text { (SD) }\end{array}$ \\
\hline $0 \mathrm{~h}$ & 0.06 & 0.97 \\
$48 \mathrm{~h}$ & 0.82 & 0.62 \\
10 days & 3.01 & 11.10 \\
& & \\
1 & 1.01 & 5.50 \\
3 & 0.01 & 9.14 \\
5 & 1.55 & 9.19 \\
7 & 0.81 & 12.23 \\
8 & 0.09 & 7.68 \\
9 & 0.09 & 8.16 \\
10 & 0.55 & 16.84 \\
11 & 0.88 & 9.20 \\
12 & 1.28 & 28.89 \\
13 & 0.20 & 21.16 \\
17 & 1.76 & 5.19 \\
20 & $<0.001$ & 10.17 \\
33 & 0.17 & 5.56 \\
38 & 13.24 & 26.91 \\
43 & 0.19 & 8.04 \\
47 & 0.10 & 9.52 \\
50 & 0.49 & 3.53 \\
72 & 0.15 & 4.67 \\
& & \\
PHA & $\mathrm{ND}$ & $14.18( \pm 7.45)$ \\
pSV & $\mathrm{ND}$ & $12.29( \pm 5.29)$ \\
\hline
\end{tabular}

${ }^{a}$ Values represent levels of CAT activity of infected cells relative to that of uninfected cells.

${ }^{b} \mathrm{ND}$, not determined. purpose, DNAs extracted from transfected Jurkat and $\mathbf{J}_{\text {vac }}$ cells were digested with restriction enzymes that distinguish between the input methylated $\mathrm{pHIV/CAT} \mathrm{produced} \mathrm{in} \mathrm{bac-}$ teria and any unmethylated $\mathrm{pHIV/CAT}$ produced by replication in eukaryotic cells. DpnI and NdeII are two enzymes which recognize the same 4-base G-A-T-C sequence, but DpnI cleaves only when the A residue is methylated at the 6 position and NdeII cleaves when it is unmethylated. Results from these experiments are shown in Fig. 4. The pHIV/CAT was digested by DpnI (lane 9), although some high-molecular-weight material remained undigested, but was not digested by NdeII (lane 10). DNAs harvested from either infected or control cells $48 \mathrm{~h}$ after transfection were completely digested by DpnI (lanes $1,3,5$, and 7) but not by NdeII (lanes $2,4,6$, and 8 ). Conversely, vaccinia virus DNA

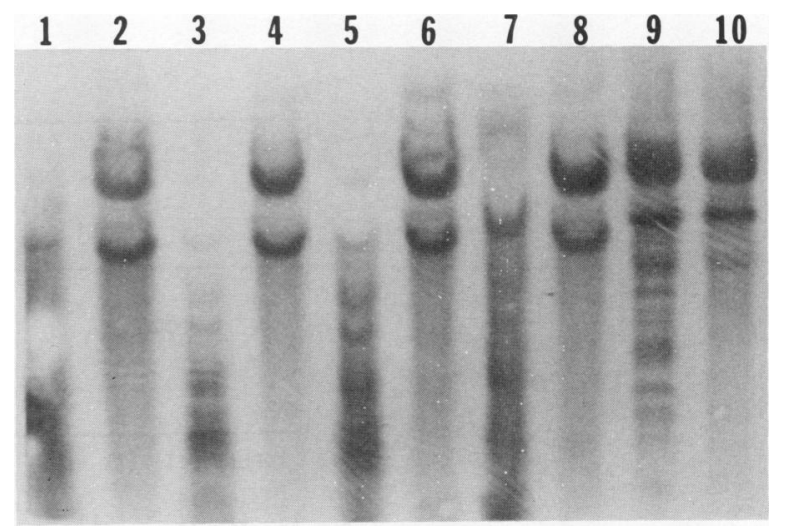

FIG. 4. Restriction enzyme analysis of pHIV/CAT extracted from transfected cells. DNA was extracted from transfected Jurkat cells (lanes 1 and 2) or from two $J_{\text {vac }}$ cell lines at passage 33 (lanes 7 and 8) and passage 67 (lanes 5 and 6). The DNA digested with DpnI (lanes 1, 3, 5, 7, and 9) or NdeII (lanes 2, 4, 6, 8, and 10) was separated by agarose electrophoresis, transferred to nitrocellulose, and hybridized with a ${ }^{35} \mathrm{~S}$-labeled pHIV/CAT probe. DNAs from PHA-treated Jurkat cells (lanes 3 and 4) and from pHIV/CAT digested with DpnI (lane 9) or NdeII (lane 10) were also included. 
A

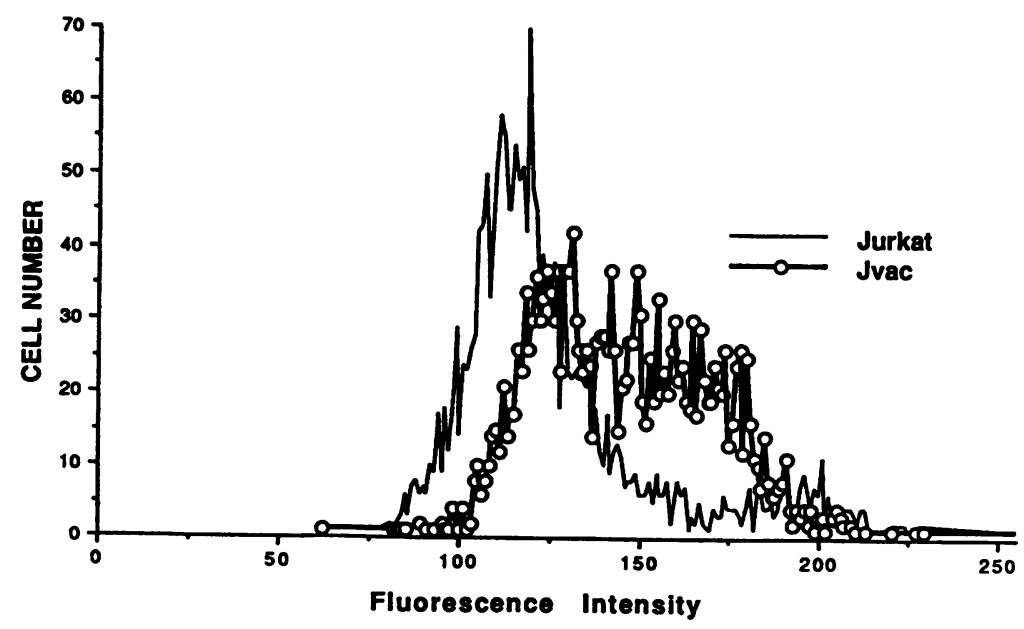

B
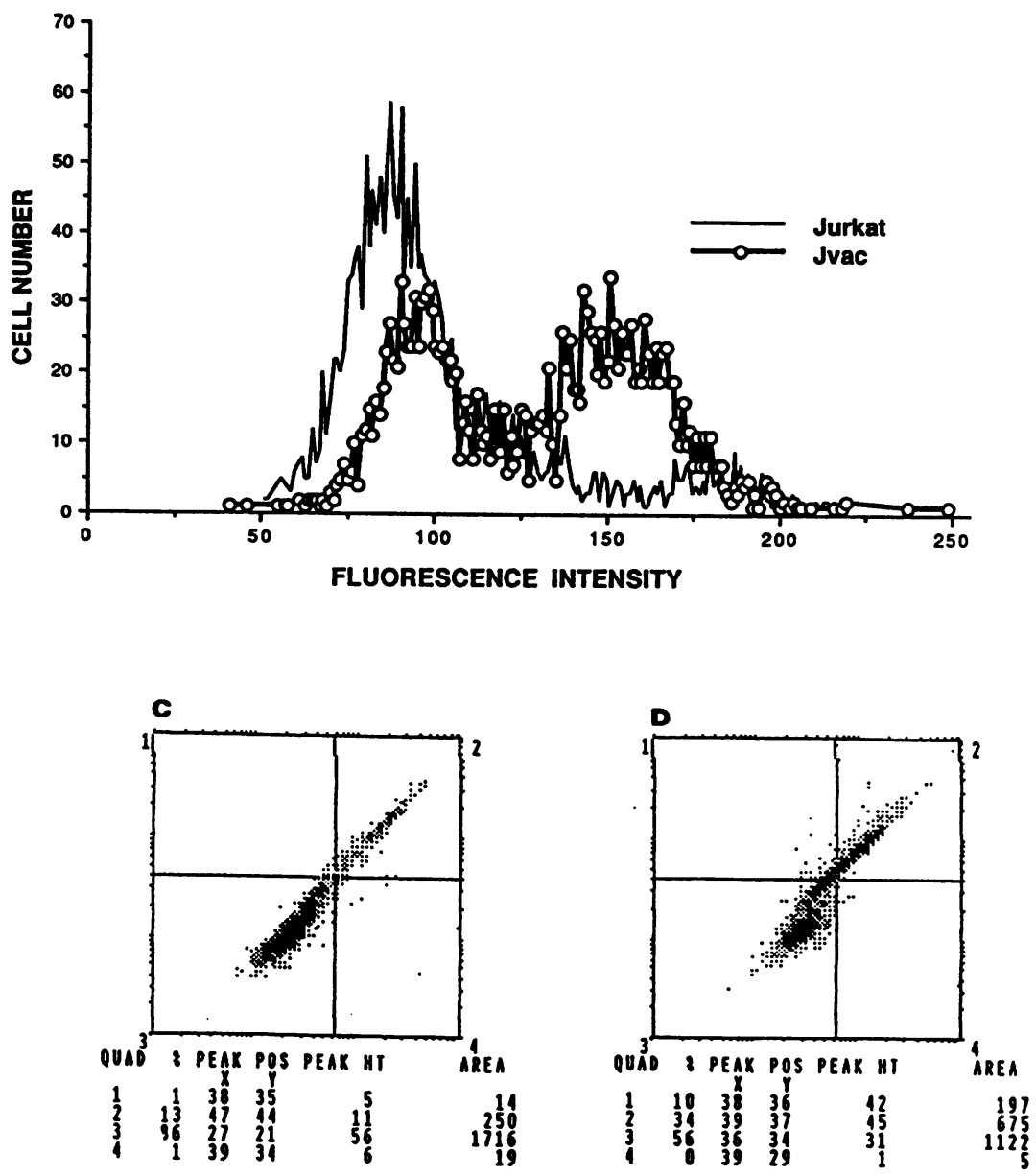

FIG. 5. CAT expression in infected cells as demonstrated by dual intracytoplasmic staining and FACS analysis. Polyclonal rabbit anti-vaccinia virus antiserum and polyclonal rabbit anti-CAT antiserum were used to stain both Jurkat and $J_{\text {vac }}$ cells. Staining patterns of Jurkat cells with anti-CAT antibodies (A) and with anti-vaccinia virus antibodies (B) and comparisons of the dual staining of Jurkat (C) and $\mathrm{J}_{\mathrm{vac}}$ cells (D) are shown. 
was digested by NdeII but not by DpnI (data not shown). These findings indicate that the pHIV/CAT DNA in vaccinia virus-infected cells is methylated and therefore comes from a prokaryotic rather than a eukaryotic source. Furthermore, the levels of radioactivity in Jurkat and $J_{\text {vac }}$ cells $48 \mathrm{~h}$ after transfection with ${ }^{35}$ S-labeled pHIV/CAT DNA were similar, indicating that there was no difference in the amount of degradation of transfected DNA in the two cell lines, nor was there a difference in the efficiency of transfections (data not shown).

Restriction of CAT expression to infected cells. FACS analysis has demonstrated that about $40 \%$ of the $\mathrm{J}_{\mathrm{vac}}$ cells are infected (36a); hence, we sought to address the question of whether HIV LTR-directed CAT expression was restricted to the infected cells. For that purpose, $J_{\text {vac }}$ and Jurkat cells transfected with pHIV/LTR/CAT DNA were analyzed simultaneously for viral infectivity and CAT activity by dual intracytoplasmic staining with anti-vaccinia virus and anti-CAT antibodies and subjected to FACS. The histogram in Fig. 5 shows that a large number of $\mathrm{J}_{\text {vac }}$ cells reacted with the CAT antiserum (Fig. 5A), but only half of these cells reacted with the vaccinia virus antiserum (Fig. 5B). When the staining patterns of both antibodies were compared, it was evident that the CAT-expressing cells were infected (Fig. 5C and D).

\section{DISCUSSION}

In these studies, we have examined the effect of vaccinia virus infection on the regulatory sequences governing HIV expression. The results indicated that cells infected with vaccinia virus are quite efficient at expressing the CAT gene under the direction of the HIV LTR to a level equal to or greater than that seen in PHA-stimulated cells (Fig. 1 and 2). The effect of vaccinia virus infection on CAT expression was not observed during the first week of infection but was recorded 10 days postinfection. Although no correlation between virus titers and levels of CAT activity could be made, it was evident that the ability to activate CAT varied from passage to passage, as did virus titers. In some passages, the CAT activity in $\mathbf{J}_{\mathrm{vac}}$ cells was 30 -fold greater than that in control cells (Table 1 ).

Although it has been reported that plasmid replication occurs in poxvirus-infected cells (9), there was no proof that this takes place in $\mathbf{J}_{\mathbf{v a c}}$ cells. Digestion of DNA extracted from transfected $J_{\text {vac }}$ cells with restriction enzymes that distinguish between methylated and unmethylated DNAs demonstrated that the pHIV/CAT DNA was indeed from a prokaryotic source (Fig. 4). This finding, however, does not contradict previous reports that indicate that leporipoxviruses are much more efficient at inducing plasmid replication than orthopoxviruses, such as vaccinia virus (9). In fact, Cochran et al. did not detect plasmid replication in vaccinia virus-infected cells (6).

Results shown in Fig. 5 indicate that half of the $\mathrm{J}_{\text {vac }}$ cells were infected (Fig. 5B), although a larger number of cells expressed CAT antigens (Fig. 5A). These findings can be explained either by the presence of a factor(s) released by the infected cells that activated the noninfected cells or by the excessive reactivity of polyclonal antibody to CAT, resulting in some false-positive cells (Fig. 5C). Experiments in which Jurkat cells transfected with pHIV/CAT were incubated with virus-free 10 -fold-concentrated conditioned media from $\mathrm{J}_{\text {vac }}$ cell cultures demonstrated that the expression of the plasmid was not stimulated. Therefore, the large number of cells stained with anti-CAT is most likely due to the reactivity of the CAT polyclonal antibody. Nevertheless, it is evident that CAT expression takes place in vaccinia virus-infected cells.

Numerous heterologous viruses have been demonstrated to activate HIV replication, including adenovirus, cytomegalovirus, Epstein-Barr virus, hepatitis B virus, human herpesvirus 6 , herpes simplex virus types 1 and 2 , papillomavirus, papovavirus, and varicella-zoster virus, and some of the viral products responsible have been identified $(1,2,8,11$, $12,16,19,22,27,29,31,32,39)$. The mechanism by which vaccinia virus activates the HIV LTR is still unknown. It is possible that a viral product induces mitogenesis of the $T$ cells and that HIV expression is a consequence of T-cell activation. Indeed, many virokines, including a viral growth factor, with cell-proliferative capabilities have been demonstrated $(4,38)$. Also, sequencing of the vaccinia virus genome has revealed open reading frames with sequence homology to tumor necrosis factor (17) and lectinlike proteins (4a). In fact, increased IL-2, IL-6, and IL-2R expression in the persistently infected cells has been demonstrated (36a).

Vaccinia virus may have a more direct effect on the regulation of the HIV LTR. It is possible that a viral trans-acting factor activates the LTR, as shown with many other DNA viruses $(1,2,8,11,16,22,27,29,31,32,39)$. Alternatively, the virus could activate a cellular DNAbinding protein, either directly or by phosphorylation of an inhibitor, such as $I-\kappa B$, resulting in the release of NF-kB (13). Indeed, it is known that the HIV LTR and the IL-2, IL-6, and IL-2R promoters are all induced by NF-kB $(3,15$, $18,21)$. On the other hand, the promoter for gamma interferon, a gene which is not expressed in $J_{\text {vac }}$ cells but is expressed during $\mathrm{T}$-cell activation (40), does not appear to have this enhancer region (5). Experiments to determine the presence of trans-acting factors and to identify the viral sequences responsible for these effects are in progress.

\section{ACKNOWLEDGMENTS}

We gratefully acknowledge A. Pizzimenti for performing the FACS analysis, M. Siekevitz and B. Hoyos for helpful discussions and suggestions, and Dolores Klaft for excellent secretarial help.

This project was funded by grants from the National Institute of Health (CA29626), the T. J. Martell Foundation, and the Chemotherapy Foundation.

\section{REFERENCES}

1. Albrecht, M. A., N. A. DeLuca, R. A. Byrn, P. A. Schaffer, and S. M. Hammer. 1989. The herpes simplex virus immediate-early protein, ICP4, is required to potentiate replication of human immunodeficiency virus in $\mathrm{CD} 4^{+}$lymphocytes. J. Virol. 63: 1861-1868.

2. Barry, P. A., E. Pratt-Lowe, B. M. Peterlin, and P. A. Luciw. 1990. Cytomegalovirus activates transcription directed by the long terminal repeat of human immunodeficiency virus type 1 . J. Virol. 64:2932-2940.

3. Böhnlein, E., J. W. Lowenthal, M. Siekevitz, D. W. Ballard, B. R. Franza, and W. C. Greene. 1988. The same inducible nuclear proteins regulate mitogen activation of both the interleukin-2 receptor-alpha gene and type 1 HIV. Cell 53:827-836.

4. Buller, R. M. L., S. Chakrabarti, B. Moss, and T. Fredrickson. 1988. Cell proliferative response to vaccinia virus is mediated by VGF. Virology 164:182-192.

4a.Chan, Y. S., S. T. Howard, and G. L. Smith. 1990. Presented at the 8th International Conference on Poxviruses and Iridoviruses, Wintergreen, Va., 15 to 20 May 1990.

5. Ciccarone, V. C., J. Chrivia, K. J. Hardy, and H. A. Young. 1990. Identification of enhancer-like elements in human IFNgamma genomic DNA. J. Immunol. 144:725-730. 
6. Cochran, M. A., M. Mackett, and B. Moss. 1985. Eukaryotic transient expression system dependent on transcription factors and regulatory DNA sequences of vaccinia virus. Proc. Natl. Acad. Sci. USA 82:19-23.

7. Dales, S. 1963. Uptake and development of vaccinia virus in strain $L$ cells followed with labeled viral deoxyribonucleic acid. J. Cell Biol. 18:51-72.

8. Davis, M. G., S. C. Kenney, J. Kamine, J. S. Pagano, and E. S. Huang. 1987. Immediate-early gene region of human cytomegalovirus trans-activates the promoter of human immunodeficiency virus. Proc. Natl. Acad. Sci. USA 84:8642-8646.

9. DeLange, A. M., and G. McFadden. 1986. Sequence-nonspecific replication of transfected plasmid DNA in poxvirus-infected cells. Proc. Natl. Acad. Sci. USA 83:614-618.

10. Dorozynski, A., and A. Anderson. 1991. Death in vaccine trials trigger French inquiry. Science 252:501-502.

11. Ensoli, B., P. Lusso, F. Schachter, S. F. Josephs, J. Rappaport, F. Negro, R. C. Gallo, and F. Wong-Staal. 1989. Human herpes virus- 6 increases HIV-1 expression in coinfected $T$ cells via nuclear factors binding to the HIV-1 enhancer. EMBO J. 8:3019-3027.

12. Gendelman, H. E., W. Phelps, L. Feigenbaum, J. M. Ostrove, A. Adachi, P. M. Howley, G. Khoury, H. S. Ginsberg, and M. A. Martin. 1986. Trans-activation of the human immunodeficiency virus long terminal repeat sequence by DNA viruses. Proc. Natl. Acad. Sci. USA 83:9759-9763.

13. Ghosh, S., and D. Baltimore. 1990. Activation in vitro of NF-kappa B by phosphorylation of its inhibitor I kappa B. Nature (London) 344:678-682.

14. Gorman, C. M., L. F. Mofiat, and B. H. Howard. 1982. Recombinant genomes which express chloramphenicol acetyltransferase in mammalian cells. Mol. Cell. Biol. 2:1044-1051.

15. Hoyos, B., D. W. Ballard, E. Böhnlein, M. Siekevitz, and W. C. Greene. 1989. Kappa B-specific DNA binding proteins: role in the regulation of human interleukin-2 gene expression. Science 244:457-460.

16. Kenney, S., J. Kamine, D. Markovitz, R. Fenrick, and J. Pagano. 1988. An Epstein-Barr virus immediate-early gene product trans-activates gene expression from the human immunodeficiency virus long terminal repeat. Proc. Natl. Acad. Sci. USA 85:1652-1656.

17. Kotwal, G. J., A. W. Hugin, and B. Moss. 1989. Mapping and insertional mutagenesis of a vaccinia virus gene encoding a 13,800-Da secreted protein. Virology 171:579-587.

18. Libermann, T. A., and D. Baltimore. 1990. Activation of interleukin-6 gene expression through the NF-кB transcription factor. Mol. Cell. Biol. 10:2327-2334.

19. Mosca, J. D., D. P. Bednarik, N. B. Raj, C. A. Rosen, J. G. Sodroski, W. A. Haseltine, G. S. Hayward, and P. M. Pitha. 1987. Activation of human immunodeficiency virus by herpesvirus infection: identification of a region within the long terminal repeat that responds to a trans-acting factor encoded by herpes simplex virus 1. Proc. Natl. Acad. Sci. USA 84:7408-7412.

20. Moss, B. 1991. Vaccinia virus: a tool for research and vaccine development. Science 252:1662-1667.

21. Nabel, G., and D. Baltimore. 1987. An inducible transcription factor activates expression of human immunodeficiency. virus in T cells. Nature (London) 326:711-713.

22. Nabel, G. J., S. A. Rice, D. M. Knipe, and D. Baltimore. 1988. Alternative mechanisms for activation of human immunodeficiency virus enhancer in T cells. Science 239:1299-1302.

23. Obom, K. M., S. W. Popple, J. G. Holland, B. G.-T. Pogo, and C. Friend. 1986. Vaccinia virus DNA sequences in the nucleus of persistently infected Friend erythroleukemia cells. Virus Res. 5:221-234.

24. Picard, O., P. Giral, M. C. Defer, M. Fouchard, M. Morel,
M. C. Meyohas, J. Lebas, J. C. Imbert, J. Frottier, J. J. Salaun, Z. Lurhuma, B. Moss, R. C. Gallo, and D. Zagury. 1990. Aids vaccine therapy: phase I trial. Lancet 336:179.

25. Pogo, B. G.-T., and C. Friend. 1982. Persistent infection of Friend erythroleukemia cells with vaccinia virus. Proc. Natl. Acad. Sci. USA 79:4805-4809.

26. Pogo, B. G.-T., A. C.-K. Lai, M. E. Joesten, M. E. Royston, and D. Holloway. 1991. Changes in cell gene expression in human leukemia cells persistently infected with vaccinia virus. Virus Res. 19:131-138.

27. Rando, R. F., P. E. Pellett, P. A. Luciw, C. A. Bohan, and A. Srinivasan. 1987. Trans-activation of human immunodeficiency virus by herpesviruses. Oncogene 1:13-18.

28. Redfield, R. R., D. C. Wright, W. D. James, T. S. Jones, C. Brown, and D. S. Burke. 1987. Disseminated vaccinia in a military recruit with human immunodeficiency virus (HIV) disease. N. Engl. J. Med. 316:673-676.

29. Rice, A. P., and M. B. Mathews. 1988. Trans-activation of the human immunodeficiency virus long terminal repeat sequences, expressed in an adenovirus vector, by the adenovirus E1A 13S protein. Proc. Natl. Acad. Sci. USA 85:4200-4204.

30. Rigby, P. W., M. Dieckmann, C. Rhodes, and P. Berg. 1977. Labelling deoxyribonucleic acid to high specific activity in vitro by nick translation with DNA polymerase I. J. Mol. Biol. 113:237-251.

31. Seto, E., P. J. Mitchell, and T. S. Yen. 1990. Transactivation by the hepatitis $B$ virus $X$ protein depends on AP-2 and other transcription factors. Nature (London) 344:72-74.

32. Seto, E., T. S. Yen, B. M. Peterlin, and J. H. Ou. 1988. Trans-activation of the human immunodeficiency virus long terminal repeat by the hepatitis $B$ virus $X$ protein. Proc. Natl. Acad. Sci. USA 85:8286-8290.

33. Siekevitz, M., S. F. Josephs, M. Dukovich, N. Pefier, F. WongStaal, and W. C. Greene. 1987. Activation of the HIV-1 LTR by $\mathrm{T}$ cell mitogens and the trans-activator protein of HTLV-I. Science 238:1575-1578.

34. Southern, E. M. 1975. Detection of specific sequences among DNA fragments separated by gel electrophoresis. J. Mol. Biol. 98:503-517.

35. Sperber, K., J. Bauer, A. Pizzimenti, V. Najfeld, and L. Mayer. 1990. Identification of subpopulations of human macrophages through the generation of human macrophage hybridomas. J. Immunol. Methods 129:31-40.

36. Sperber, K., S. K. Goswami, E. Gollub, L. Mayer, and Z. Maron. 1991. Mucus secretagogue production by a human macrophage hybridoma. J. Allergy Clin. Immunol. 87:4390 4398.

36a.Stellrecht, K. A., K. Sperber, and B. G.-T. Pogo. 1992. Stimulation of lymphokines in Jurkat cells persistently infected with vaccinia virus. J. Virol. 66:2046-2050.

37. Turner, P. C., and R. W. Moyer. 1990. The molecular pathogenesis of poxviruses. Curr. Top. Microbiol. Immunol. 163:125151.

38. Twardzik, D. R., J. P. Brown, J. E. Ranchalis, G. J. Todaro, and B. Moss. 1985. Vaccinia virus-infected cells release a novel polypeptide functionally related to transforming and epidermal growth factors. Proc. Natl. Acad. Sci. USA 82:5300-5304.

39. Twu, J. S., and W. S. Robinson. 1989. Hepatitis B virus X gene can transactivate heterologous viral sequences. Proc. Natl. Acad. Sci. USA 86:2046-2050.

40. Ullman, K. S., J. P. Northrop, C. L. Verweij, and G. R. Crabtree. 1990. Transmission of signals from the T lymphocyte antigen receptor to the genes responsible for cell proliferation and immune function: the missing link. Annu. Rev. Immunol. 8:421-452. 